The book is divided into four parts, with the first part dedicated to general guidelines on getting started in research and a chapter on writing up research for publication. The second part focuses on different types of research design including systematic review and meta-analysis, epidemiology, qualitative research and research with single or few patients. The third part of the book explains the tools required for psychiatric research including rating scales, statistics, use of computers and principles of psychological assessment. The final part covers research in special groups, including children and adolescents, learning disability, psychotherapy and historical research.

The chapter on 'Getting started in research', written by the editors themselves, is very motivating and will encourage trainees at any stage to consider taking up research. The essential information on the practicalities of conducting research, such as organising supervision, maintaining a research diary and applying for a research ethics committee approval, is provided in a concise manner. The fact that one of the editors of the book is also the current editor of the British Journal of Psychiatry makes 'Writing up research' all the more valid and interesting. 'Psychiatric research from the trainee's perspective' details the problems faced by trainees and provides solutions to most of them.

The information on different research designs is clear and succinct. Research methodology in the sub-specialties is covered in adequate detail and I found the chapter on research in psychotherapy to be particularly impressive. Although mentioned in the preface, a chapter on research in old age psychiatry is not included but would have made this section complete.

The chapters on 'Using computers in research' and 'Statistical aspects of clinical trials in psychiatry' are the only disappointments in this book for me. The former is too brief to make the point clearly, and the latter is too broad and lacking in focus. Some parts of the statistics chapter are a repetition of what is already covered. The chapter on rating scales is a compilation of the most relevant rating scales used in psychiatry, which will be of great value to any researcher, whether old or new.

There are many problems that trainees cite as reasons for not getting involved in research. This book seems to provide solutions to many of those problems and supplies further reasons for trainees to become involved in research. It will be of immense help to any trainee about to embark on research in psychiatry.

Petrie, R., Anderson, K., Hare, E., et al (2004) Research activity of specialist registrars. Psychiatric Bulletin, 28, 180-182.

Pavan Mallikarjun Unniversity of Notthingham, Queens Medical Centre, Division of Psychiatry, South Block, A Floor, Nottingham NG7 2UH, UK. Email: pavan.mallikarjun@nottingham.ac.uk doi: 10.I192/bjp.bp.107.036095

\section{Textbook of Men's Mental Health}

Edited by Jon E. Grant \& Marc N. Potenza. American Psychiatric Publishing. 2007. 468 pp. US\$75.00 (hb). ISBN I585622I5X

Q. Why does it take 45 million sperm to fertilise one egg?

A. Because none of them will ask the way.

Males have a problem in asking for help. This is a serious disadvantage given that, on almost all measures, we are more vulnerable than females to biological or psychological challenges. Men tend to rely on women to get them to doctors, and indeed to keep them socialised and in contact with their own children, even if they are not fully aware of this.

This is a psychiatric and psychological textbook, not a medical one, though pharmacological and neurodevelopmental issues are well covered. The missing link is the evolutionary theme, which is not explored at all. Men die before women (Barford et al, 2006), boys more than girls, and male before female foetuses. A more cohesive society reduces some of these differences (Westerling, 2003). Apart from neural tube defects and chromosomal abnormalities, everything that can go wrong from conception to delivery is more likely to affect the male. While many more males than females are conceived, the gap has diminished by the time of birth. Under severe stress (such as war or natural disaster) the male:female ratio at birth falls further (Catalano et al, 2006). Death, damage and disease are more common (or more severe) in males throughout their lifespan (Kraemer, 2000; Rutter et al, 2003).

The $\mathrm{Y}$ chromosome is a poor thing but with two Xs, females are endowed with what is in effect a spare battery (Christensen et al, 2001). In nature, the majority of males are redundant. Successful mating in most mammalian species is the preserve of only the most successful highranking individuals. In contrast, there are far more opportunities for human males to procreate but being a man is more complicated. In modern societies masculinity is fragile, when for so many men, except in sport and furniture removal, non-violent, physical superiority is of little value (Kraemer, 1995).

None of these evolutionary data are acknowledged in the text, a significant omission. Apart from that, the scientific and psychological material is up to date and thorough though the clinical advice is rather pedestrian. The suggestion (p. 57) that older men would be more likely to accept psychiatric care if it were integrated with medical services makes good sense, however. There are lively case vignettes in each chapter but, oddly, these are not taken up in the subsequent text. They are worth reading on their own.

A thicker corpus callosum in women (p. 285) may aid richer left-right communication in their brains. Whatever the reason, women tend to make more social connections too:

\footnotetext{
... in response to a depressed mood, men would be more likely to avoid thinking about why they were depressed, to take drugs, or to do something physical, whereas women would try to determine why they were depressed, talk to others about how they were feeling, or cry' (p. 99).
}

Throughout life stressed males tend to be irritable and restless. The reason why more men than women kill themselves is not

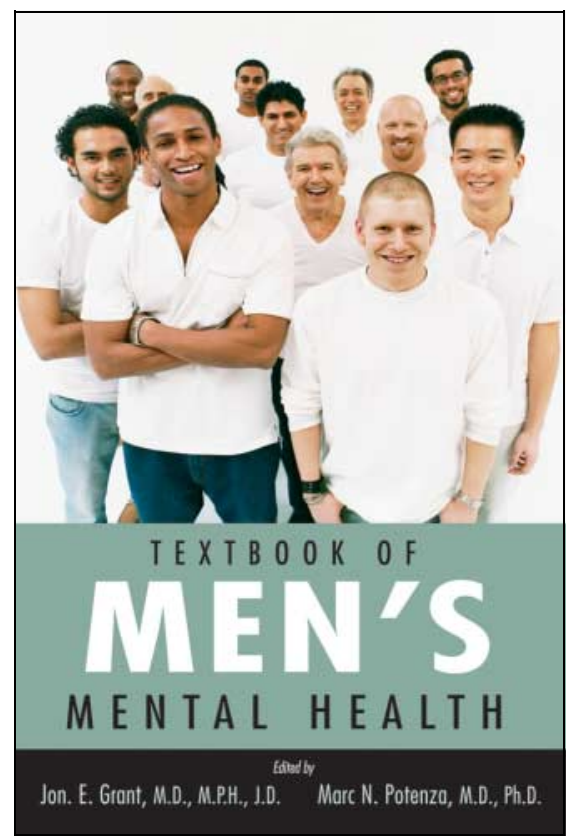


simply owing to greater impulsivity (p. 26) or the more violent and efficient methods chosen (p. 99), but also to a prevailing belief that no one will be there to help.

Barford, A., Dorling, D., Davey Smith, G., et al (2006) Life expectancy: women now on top everywhere. BMJ, 332, 808

Catalano, R., Bruckner, T., Marks, A. R., et al (2006) Exogenous shocks to the human sex ratio: the case of September II, 200I in New York City. Human Reproduction, 21, 3127-313

Christensen, K., Ørstavik, K. H. \& Vaupel, J.W. (200I) The $X$ chromosome and the female survival advantage: an example of the intersection between genetics, epidemiology and demography. Annals of the New York Academy of Sciences, 954, 175-183

Kraemer, S. (1995) A man's place. In Women, Men and Marriage (ed. C. Clulow). Sheldon Press.

Kraemer, S. (2000) The fragile male. BMJ, 32I, 16091612

Rutter, M., Caspi, A. \& Moffitt, T. E. (2003) Using sex differences in psychopathology to study causal mechanisms: unifying issues and research strategies. Journal of Child Psychology and Psychiatry, 44, 1092-III5.

Westerling, R. (2003) Decreasing gender differences in avoidable mortality in Sweden. Scandinavian Journal of Public Health, 31, 342-349.

Sebastian Kraemer Child and Family Psychiatric Service, Whittington Hospital, London NI9 5NF, UK. Email: kraemer@doctors.org.uk doi: 10.II92/bjp.bp.107.033829

\section{The Mindful Way through Depression: Freeing Yourself from Chronic Unhappiness}

By Mark Williams, JohnTeasdale, Zindel Segal \& Jon Kabat-Zinn. Guilford Publications. 2007. 278pp. US \$19.95 (pb). ISBN 9781593851286

Freeing ourselves from unhappiness, or, if we have done that and got the T-shirt,

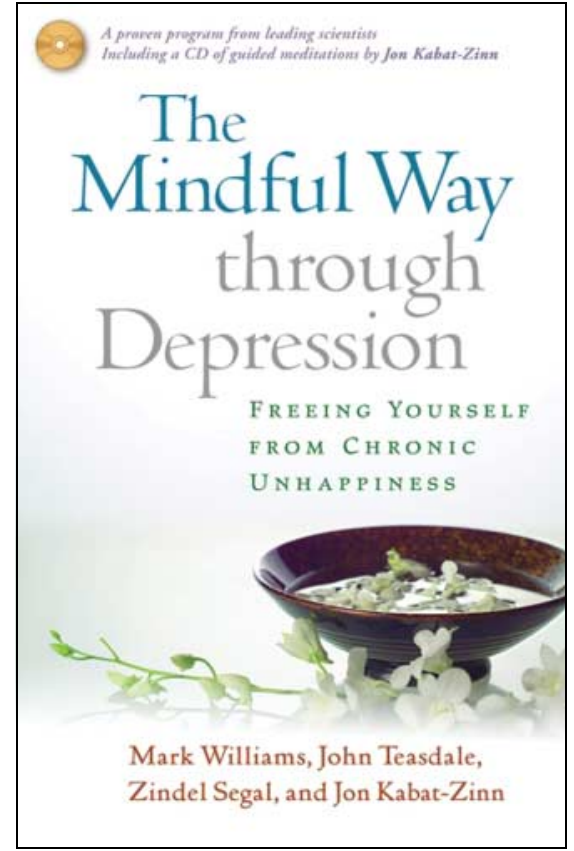

freeing others from chronic unhappiness sounds like a worthwhile effort. Mindfulness Based Cognitive Therapy (MBCT), a group skill-training for relapse prevention of depression, has been shown to halve relapse rates in chronic depression in two randomised controlled trials and is endorsed by the National Institute for Health and Clinical Excellence (NICE). Williams et al have published their eagerly awaited book accompanying the MBCT group programme and explaining their ground-breaking therapy to users and professionals.

Every word in this affordable paperback seems to embody the gentleness and the spirit of openness that one brings to the practice of MBCT. It is therefore an ideal tool for guided self-help. Like learning a new musical instrument, it encourages readers to immerse themselves in various meditative practices. Via a CD sold with the book, readers are guided by the calming voice of Jon Kabat-Zinn - the man who brought meditation into the medical mainstream and made it accessible to scientific evaluation.

Invaluable for all non-professionals and therapists alike, The Mindful Way through Depression takes the reader step by step on a journey of exploration. It gives us a rationale for trying this programme: depressive relapse is mediated by the mind's habit of trying to solve problems that cannot be resolved. By brooding over the past, or worrying about the future, our mind takes us into an internal battle that cannot be won - away from the experience of what is the present moment, into a depressive spiral. This therapy is a way out of the ruminative spiral through a paradoxical intervention: by not trying to change the way we feel we create a space where healing can take place. Skills known from cognitive-behavioural therapy, like behavioural activation and seeing thoughts as thoughts rather than ultimate truths, are elegantly intertwined with meditative techniques.

The book ultimately helps us to make contact with a truly revolutionary concept that seems so alien to our culture and to us as health professionals - deeply felt acceptance of feelings or states that we cannot change. Not convinced? Just get the book, get your bottom on the cushion and read it. Do it in the spirit of this book: 'You do not have to like it, just do it!' You may enjoy it after all.

Florian Alexander Ruths South London and Maudsley NHS Trust, David Pitt House, 24-28 Norwood High Street, London SE27 9NR, UK

Email: florian.ruths@slam.nhs.uk doi: 10.1192/bjp.bp.107.039560 